\title{
DFT Based Comparative Studies of Some Glucofuranose and Glucopyranoside Esters and Ethers
}

\author{
Sreebash C. Bhattacharjee ${ }^{a, *}$, Md. H.O. Roshid ${ }^{b}$, Md. Atiquel Islam Chowdhury ${ }^{c}$ and \\ Mohammed Belal Hossain ${ }^{d}$ \\ ${ }^{a}$ Chemical Research Division, Bangladesh Council of Scientific \& Industrial Research \\ (BCSIR) Laboratories, Chattogram, 4220, Bangladesh \\ ${ }^{b}$ Department of Anesthesia and Intensive Care, Chattogram Medical College, Chattogram, \\ 4203, Bangladesh \\ ${ }^{c}$ Department of Medicine, Southern Medical College, Chittagong, 4209, Bangladesh \\ ${ }^{d}$ Department of Chemistry, Faculty of Science, University of Chittagong, Chittagong, 4331, \\ Bangladesh
}

\begin{abstract}
Carbohydrate-based molecular scaffolding received significant interest due to its impact on the drug discovery and development in synthetic carbohydrate chemistry during the last couple of decades. In this respect, four glucose compounds in the furanose and pyranose forms with ester and ether functionality were selected for their structural, thermodynamic and chemical reactivity studies. PASS predication indicated that the glucose in the six-membered pyranose form was more prone to biological properties compared to their five-membered furanose form. Also, in the pyranose form acetate ester (3) had more potentiality than the ethyl ether (4). The HOMO-LUMO energy gaps were almost similar for both monosubstituted furanose and pyranose glucose indicating their almost similar reactivities. It was also inferred that these 6-O-substituted compounds followed Lipinski's rule with the acceptable range of ADMET levels, and hence, safe from lethal proarrhythmic risks. Hopefully, these results can be used in the near future for their probable pharmaceutical use without any remarkable toxicity.
\end{abstract}

Keywords: Glucofuranose, Glucopyranoside, DFT, Sugar esters, Sugar ethers.

\section{Introduction}

Carbohydrates and their derivatives are of significant interest as many of them cover the surface of cells and expose the cell-cell recognition process [1-2] leading to the formation of major classes of biologically operative molecules [1-4]. Their comprehensive chemical nature, biological, and pharmacological interactions for a better understanding of their functions in a large number of essential biological events have been reported [5-8]. Compared to other synthetic bioactive compounds, they have less nitrogen and halogen atoms whereby they possess more oxygen atoms which impose more biological relevance. Thus, a considerable extent of simple carbohydrates or their derivatives, glycoconjugates, glycohybrids, and neoglycoconjugates have been evaluated worldwide

\footnotetext{
* Corresponding author. Tel.: +880 1993 148409; https://orcid.org/0000-0002-2617-5816

E-mail address: sreebashcu2016@gmail.com

Manuscript History:

Received 9 August, 2021, Revised 27 August, 2021, Accepted 15 September, 2021, Published 31 October, 2021

Copyright (C) 2021 UNIMAS Publisher. This is an open access article under the CC BY-NC-SA 4.0 license.

https://doi.org/10.33736/jaspe.3786.2021
}

e-ISSN: 2289-7771

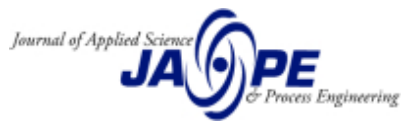


for the fortunate treatment of numerous influential diseases [9,10] including vaccines against infectious diseases [10]. In general, the addition of sugar moieties in these drugs (nystatin A1, and amphotericin B) lead to higher solubility and lower hemolytic toxicity (anaemia) although biological activities of these polyene antifungals depend on the number and type of extended second sugar residue [11]. The lower hemolytic toxicity is helpful to generate new mechanisms and strategies for antitumor agents [11].

The discovery of carbohydrate-based new bioactive molecules (e.g. topiramate, kanamycin, tobramycin, clindamycin etc.) established on screening of analogue libraries and the structure-activity relationship has been accomplished by a range of chemical procedures [12-16]. Concerning carbohydrate chemistry, the generation of potential substrates/inhibitors for a range of different enzymes enables them for multivalent interactions with defined target proteins for selective labelling of biomolecules either in cells or within living organisms [17]. Due to the highly specific interactions with physiological receptors carbohydrates, especially acyl and alkyl glycoses take part in many crucial biological processes [18-20]. These redesigned glycoses have attracted valuable research interest and extensive applications in industries and medicine mainly due to their considerable insecticidal and antimicrobial activities [21-23]. Of them, glucose derived esters and ethers are found to be of great significance [24-28].

The recent outbreak of COVID-19 (coronavirus disease of 2019) and exposure of multi-drug resistant (MDR) pathogenic bacteria and fungi (e.g. black fungus) are global concerns. Additionally, many new obstacles are reported for modern medicines by these MDR pathogens at the site of drug delivery positions. In this pandemic situation to overcome the effects of these MDR pathogens, there is a desperate need for the formulation of newer chemotherapeutic drugs with a safer mode of action (MoA). In this respect as well as continuous effort in the synthesis, structural identification, properties and applications of carbohydrate molecules [29-32] from this laboratory, the DFT (Density Functional Theory) based comparative studies of glucofuranose and glucopyranose esters and ethers along with ADMET (Absorption, Distribution, Metabolism, Excretion, and Toxicity) are reported herein.

\section{Materials and methods}

\subsection{Glucofuranose and glucopyranose 1-4}

In the present study, two glucofuranose compounds namely 6-O-acetyl-1,2- $O$-isopropylidene- $\alpha$ D-glucofuranose (1) and 6-O-ethyl-1,2-O-isopropylidene- $\alpha$-D-glucofuranose (2); and two glucopyranose compounds namely methyl 6-O-acetyl- $\alpha$-D-glucopyranoside (3) and methyl 6-O-ethyl$\alpha$-D-glucopyranoside (4) were chosen for DFT optimization and related thermodynamic studies (Figure 1).
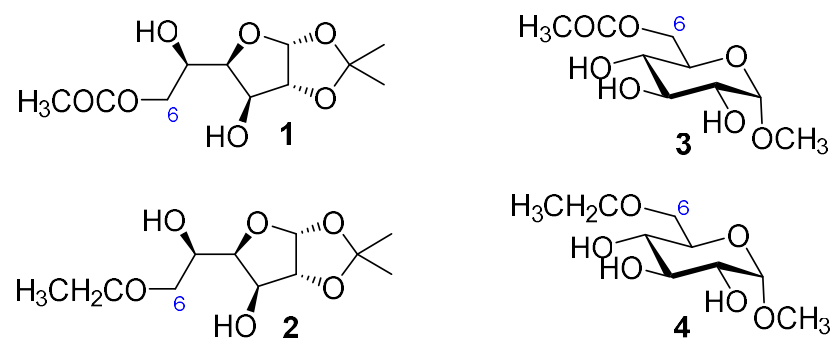

Figure 1. Structure of glucose-derived compounds 1-4.

\subsection{Predication of activity spectra for substances}

The structures of the target compound 1-4 were drawn in ChemDraw. These were then

e-ISSN: 2289-7771

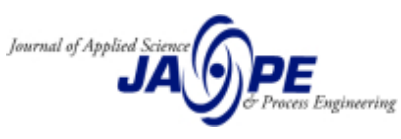


converted into their respective SD (standard data) file format(s). These SD files were separately used to predict the biological spectrum using the PASS (prediction of activity spectra for substances) online version. Many online oriented programs are freely available [33]. Here, online-built PASS (http://www.pharmaexpert.ru/ PASSonline/index.php) was designated for the predication purpose of biologically related properties of the glucose derived 1-4 [33-35]. This PASS program was widely applied to anticipate around 4000 types of biological pursuit with higher precision (above 95\%). In this resource, its calculations were presented by the $\mathrm{Pa}$ (probability for active compound, 0.000 to 1.000 ) and $\mathrm{Pi}$ (probability for inactive compound, 0.000 to 1.000). Potential compounds were screened as $\mathrm{Pa}>\mathrm{Pi}(\mathrm{Pa}+\mathrm{Pi} \neq 1)$ for any organic molecules. Based on $\mathrm{Pa}$ values, several recommendations for possibilities of biological activities were described [33-35]. For example, $\mathrm{Pa}>0.7$ was interpreted as the higher probability to find a similar activity experimentally. Also, $\mathrm{Pa}<0.5$ was interpreted as the lower chance to get the activity under experimental conditions. These recommendations were based on the information obtained from more than three million bioactive compounds [36]. On the basis of all these aspects, PASS be considered as the intrinsic property of any potential drug compound [3639].

\subsection{Density Functional Theory (DFT) optimization}

At first, appropriate stereochemistry of glucofuranose and glucopyranose were downloaded from the online Chemspider server. Keeping geometry (stereochemistry) intact acetyl and ethyl compounds 1-4 were duly depicted in Gauss View (5.0) software [40]. Having appropriate drawings 14 were separately subjected for optimization using the most popular density function theory (DFT). The method used was B3LYP (Becke, 3-parameter, Lee-Yang-Parr). The basis set was 6-31G+ in the Gaussian 09 program in a Corei5 laptop which took 2-3 days for each compound [41,42]. Optimized structures were saved for the next step use.

\subsection{Calculation of chemical reactivity descriptors}

GaussView 5.0.8. was used to calculate the HOMO (Highest Occupied Molecular Orbital) and LUMO (Lowest Unoccupied Molecular Orbital) energy levels (eV) [43,44]. These values were ultimately used to calculate other chemical reactivity and descriptors. In this regard, well-accepted literature equations like the Parr, and Pearson interpretation of DFT and Koopmans theorem were followed [45] such as, ionization potential (I) $=-\varepsilon H O M O$, and electron affinity $(\mathrm{A})=-\varepsilon L U M O$. Additionally, energy gap $(\Delta \varepsilon)=\varepsilon L U M O-\varepsilon H O M O ;$ chemical potential $(\mu)=-(\mathrm{I}+\mathrm{A}) / 2$; electronegativity $(\chi)=(I+A) / 2$; hardness $(\eta)=(I-A) / 2$; softness $(S)=1 / \eta$; electrophilicity $(\omega)=\mu^{2} / 2 \eta$.

\subsection{ADMET and drug-likeness prediction}

In silico screening approaches using the pkCSM model, were reported to be the best software to calculate different pharmacokinetic property classes [46]. This graph-based software also calculated the toxicity of compounds as a safety model [46]. Absorption, distribution, metabolism, excretion, and toxicity (ADMET) were important criteria for pharmaceutical analysis. The poor ADMET model was a significant hurdle in the drug development process. Prediction of ADMET of any compound provided advanced drug-related information and hence was able to evade the enormous financial cost and time connected to the in vivo laboratory tests. In recent years, computational techniques have been widely used for ADMET calculations ahead of organic synthesis. As mentioned in Section 2.4, structures of all glucopyranose and glucopyranosides were correctly drawn in the ChemDraw programme to collect their isomeric SMILES (simplified molecular-input line-entry system), and SD file formats. Using these formats, ADMET of all the glucose was predicted. Online based two web servers were employed in the present study namely pkCSM-pharmacokinetics 
(http://biosig.unimelb.edu.au) and SwissADME (http://www.swissadme.ch) [47]. In the process of physicochemical filters, AdmetSAR online server was also used to predict the ADMET properties of all drugs $[48,49]$.

\section{Results and discussion}

\subsection{DFT optimized structures of 1-4}

Both the furanose and pyranose forms of glucose esters and ethers were optimized by the "Becke, 3-parameter, Lee-Yang-Parr" (B3LYP) method and 6-31G+ basis set in Gaussian 09 program. The accurate exchange energy functional was presented in terms of the Kohn-Sham orbitals where the most commonly used versions were B3LYP [50]. B3LYP reproduced the geometries of smaller and larger molecules very well. The optimized geometrical structures are shown in Figure 2.

In the glucofuranose $\mathbf{1}$ and 2, 1,2-O-isopropylidene groups were found below the furanose ring while 6-O-acetyl and 6-O-ethyl groups were found above the furanose ring. In glucopyranoside 3 and 4, the 6-O-acetyl and 6-O-ethyl groups were also situated above the pyranose ring. Similar to other cases, the conformation of glucopyranosides were present in ${ }^{4} C_{1}$ regular form (Figure 2). The symmetry of these pyranoside molecules was found as $\mathrm{C} 1$.
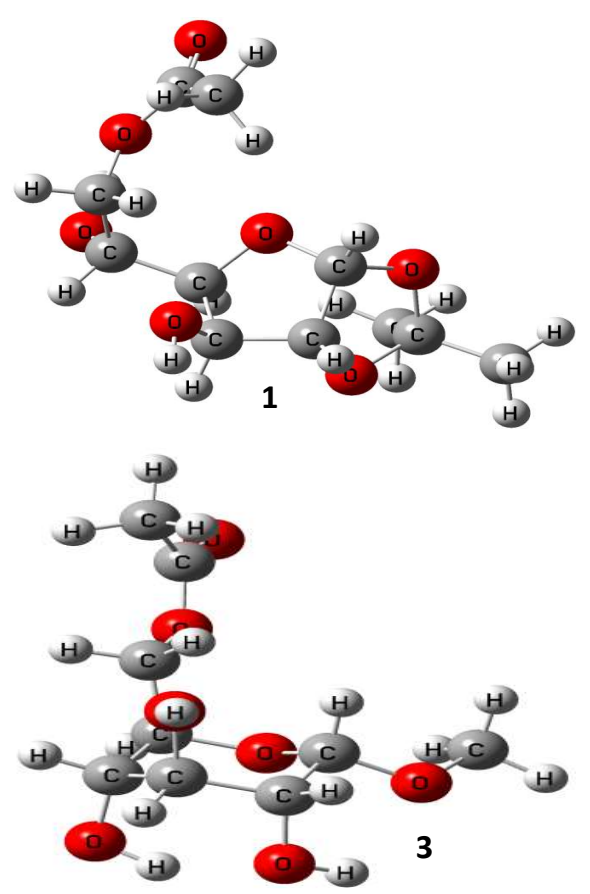
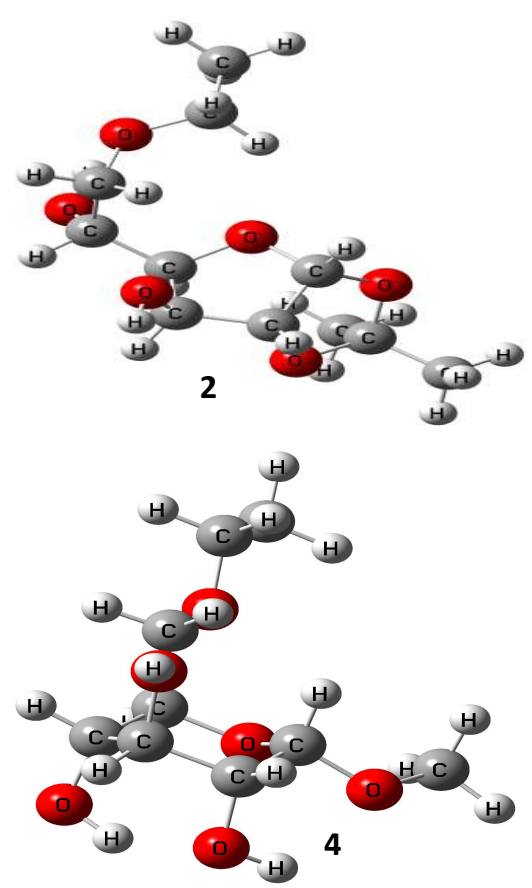

Figure 2. 6-31G+ optimized structures of modified glucose 1-4.

\subsection{PASS predicted results of 1-4}

Prediction of activity spectra for substances i.e. PASS programme is an online software product (http://www.way2drug.com/passonline/) and an important machine learning tool for assessing the universal biological potentiality of any organic drug-like molecule [33,51] and different substances $[52,53]$. Established on the structures of organic compounds PASS programme can generate concomitant predictions of multiple types of biological activities. Here, Pa (probability to be active) estimated the chance that the studied compound was linked to the sub-class of active substances.

e-ISSN: 2289-7771

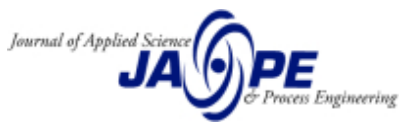


Thus, PASS was applied to predict different biological activities of the molecule 1-4 which predicted 3678 kinds of activities simultaneously having to mean accuracy of prediction above 95\% [33]. For rigorous validation, tetracycline and fluconazole were compared with the modified glucose 1-4. For simplicity, four types of activities are stated in Table 1.

Table 1. Biological information of the modified glucose 1-4 from PASS.

\begin{tabular}{|c|c|c|c|c|c|c|c|c|}
\hline \multirow{3}{*}{ Drug } & \multicolumn{8}{|c|}{ Biological activity } \\
\hline & \multicolumn{2}{|c|}{ Antibacterial } & \multicolumn{2}{|c|}{ Antifungal } & \multicolumn{2}{|c|}{ Anti-carcinogenic } & \multicolumn{2}{|c|}{ Antioxidant } \\
\hline & $\mathrm{Pa}$ & $\mathrm{Pi}$ & $\mathrm{Pa}$ & $\mathrm{Pi}$ & $\mathrm{Pa}$ & $\mathrm{Pi}$ & $\mathrm{Pa}$ & $\mathrm{Pi}$ \\
\hline 1 & 0.540 & 0.013 & 0.662 & 0.012 & 0.385 & 0.033 & 0.250 & 0.036 \\
\hline 2 & 0.486 & 0.018 & 0.627 & 0.016 & 0.294 & 0.061 & 0.208 & 0.051 \\
\hline 3 & 0.555 & 0.012 & 0.662 & 0.012 & 0.783 & 0.006 & 0.588 & 0.005 \\
\hline 4 & 0.479 & 0.018 & 0.617 & 0.017 & 0.590 & 0.013 & 0.561 & 0.005 \\
\hline TTC & 0.694 & 0.005 & 0.523 & 0.023 & - & - & - & - \\
\hline FCZ & - & - & 0.726 & 0.008 & - & - & - & - \\
\hline
\end{tabular}

$\mathrm{Pa}=$ Probability 'to be active'; $\mathrm{Pi}=$ Probability 'to be inactive'; TTC = tetracycline; $\mathrm{FCZ}=$ fluconazole.

It is evident from Table 1 that glucose in both furanose and pyranose forms were more active against fungi than bacteria. Again, acetyl esters $\mathbf{1}$ and $\mathbf{3}$ had more potential than ethyl ether $\mathbf{2}$ and $\mathbf{4}$. Encouragingly, antifungal $\mathrm{Pa}$ values of 1-4 (0.617-0.662) were higher than that of tetracycline $\mathrm{Pa}$ value (0.523). On the other hand, anti-carcinogenic and antioxidant properties of furanose ester (1) and ether (2) were found to be lower than that of pyranose ester (3) and ether (4). Overall, glucose in the six-membered pyranose form was found to possess better biological properties as compared to its five-membered furanose form. Also, pyranose acetate ester (3) had more potential than pyranose ethyl ether (4).

\subsection{Chemical reactivities of $1-4$}

In general, the chemical reactivity descriptors indicated a special significance for organic compounds with respect to their biological activities. These reactivity descriptors were calculated from their DFT optimized structures using the equations mentioned in the experimental section. As shown in Table 2, $\varepsilon L U M O, \varepsilon H O M O$ and their energy gap $(\Delta \varepsilon)$, electronegativity $(\chi)$, electron affinity (A), ionization potential (I), chemical potential $(\mu)$, hardness $(\eta)$, softness $(S)$ and electrophilicity $(\omega)$ of 1-4 indicated their comparative results.

Table 2. Molecular reactivity descriptors and FMO data of 1-4.

\begin{tabular}{ccccccccccc}
\hline Mol & $\begin{array}{c}\boldsymbol{\varepsilon} \mathbf{L U M O} \\
(\mathrm{eV})\end{array}$ & $\begin{array}{c}\boldsymbol{\varepsilon} \mathbf{H O M O} \\
(\mathrm{eV})\end{array}$ & $\begin{array}{c}\boldsymbol{\Delta} \boldsymbol{\varepsilon} \\
(\mathrm{eV})\end{array}$ & $\begin{array}{c}\mathbf{I} \\
(\mathrm{eV})\end{array}$ & $\begin{array}{c}\mathbf{A} \\
(\mathrm{eV})\end{array}$ & $\begin{array}{c}\boldsymbol{\mu} \\
(\mathrm{eV})\end{array}$ & $\begin{array}{c}\boldsymbol{\chi} \\
(\mathrm{eV})\end{array}$ & $\begin{array}{c}\boldsymbol{\eta} \\
(\mathrm{eV})\end{array}$ & $\begin{array}{c}\mathbf{S} \\
(\mathrm{eV})\end{array}$ & $\begin{array}{c}\boldsymbol{\omega} \\
(\mathrm{eV})\end{array}$ \\
\hline $\mathbf{1}$ & -0.8389 & -7.4796 & 6.6407 & 7.480 & 0.839 & -4.160 & 4.160 & 3.321 & 0.301 & 2.605 \\
$\mathbf{2}$ & -0.6223 & -6.9269 & 6.3046 & 6.927 & 0.622 & -3.775 & 3.775 & 3.153 & 0.317 & 2.260 \\
$\mathbf{3}$ & -0.8819 & -7.3574 & 6.4755 & 7.357 & 0.889 & -4.123 & 4.123 & 3.234 & 0.309 & 2.628 \\
$\mathbf{4}$ & -0.6125 & -7.0009 & 6.3884 & 7.001 & 0.613 & -3.807 & 3.807 & 3.194 & 0.313 & 2.269 \\
\hline
\end{tabular}

The molecule is indicated as Mol; LUMO stands for the lowest unoccupied molecular orbital; HOMO stands for the highest occupied molecular orbital; $\mathrm{eV}=$ electron volt.

The HOMO-LUMO energy gaps were almost similar for both monosubstituted furanose and pyranose glucose indicating their almost similar reactivities. However, 6-O-acetate $\mathbf{1}$ and $\mathbf{3}$ had slightly higher energy gaps than their corresponding 6-O-ethyl ether $\mathbf{2}$ and 4, respectively (Figure 3). All these compounds had almost similar hardness $(\eta)$ values and inversely smaller softness $(\mathrm{S})$ values (Table 2 ).

e-ISSN: 2289-7771

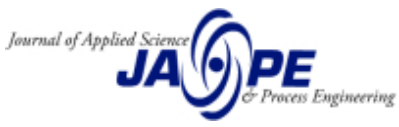


Their electrophilicity indices were found to be $\sim 2.6 \mathrm{eV}$.
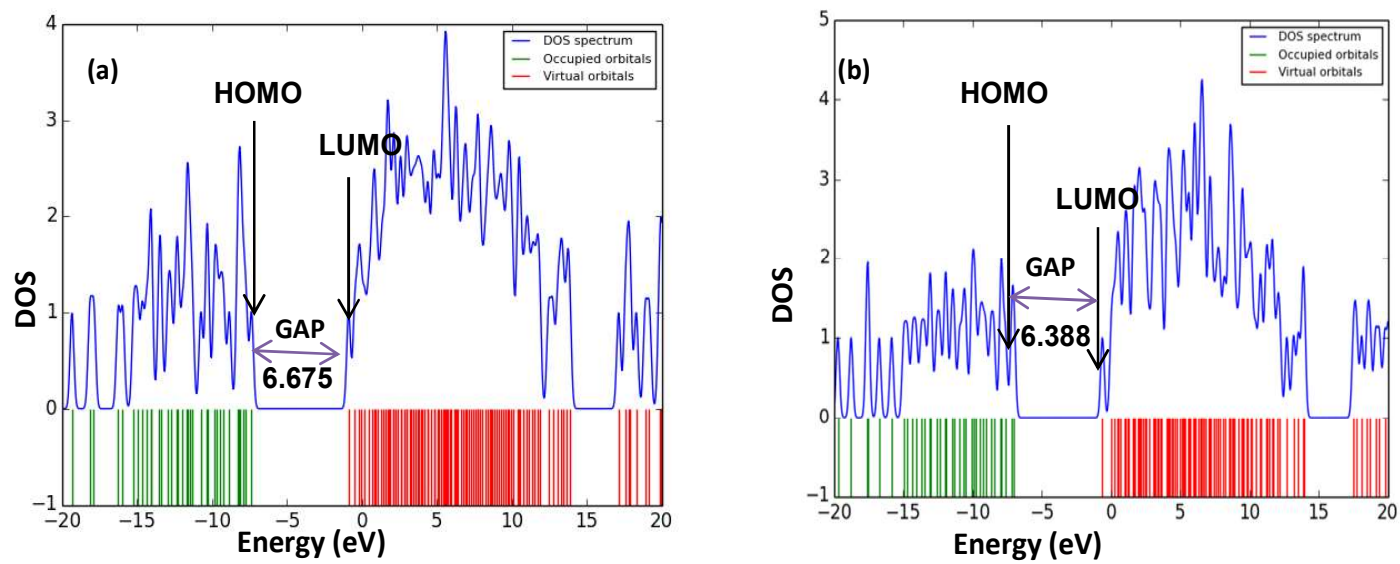

Figure 3. DOS plot interpretation for HOMO-LUMO gap of the molecule- (a) 3, and (b) 4 .

\subsection{ADMET and drug-likeness properties}

Many recent articles mentioned that the challenge, cost, and risk are associated with a low success rate of drug development [54,55]. In other words, low safety profile and poor efficacy are the two major causes of drug failure [46]. Thus, advanced prediction of ADMET (absorption, distribution, metabolism, excretion, and toxicity) of organic compounds reduce the challenge, expense, and risk in the drug discovery and development process. ADMET, in general, constitutes the pharmacokinetic profile of a drug molecule. Bayer Pharma had created a computational ADMET platform aiming to generate models for a variety of pharmacokinetic and physicochemical endpoints at the inception point of drug discovery to overcome several hurdles [56]. The computer-aided drug design (CADD) depends on the virtual screening (VS) of large compound datasets and comparing their important drug discovery protocols. Along with a rapid evaluation of ADMET, CADD protocol provides a wealth of information. Scale up of analytical power of CADD information may be helpful for fundamental investigation of health and biotechnological related problems including complementary and conventional hurdles. These hurdles can be detected more swiftly and effectively by CADD. In this study, pkCSM-pharmacokinetics (http://biosig.unimelb.edu.au) and AdmetSAR online server were used to predict the ADMET properties of all drugs $[48,49]$.

The ADMET properties, as presented in Table 3, indicated that the 6-O-substituted glucose 1-4 had good human intestinal absorption (HIA) value. Caco-2 permeability (C2P) values were also in an acceptable range. Like fluconazole, these compounds were P-glycoprotein non-inhibitor. Their distribution through the blood-brain barrier (BBB) and central nervous system (CNS) was in good agreement with standard drugs (Table 3).

Metabolism is generally expressed by five major CYP isoforms (substrate or non-substrate). Here, predicted metabolism indicated that they were non-metabolite of the CYP3A4 substrate. Predicted excretion features in the form of total clearances $(\log \mathrm{mL} / \mathrm{min} / \mathrm{kg}$ ) were in a good range. More importantly, all the substituted glucose were non-inhibitor of human Ether-a-go-go Related Gene (hERG; I \& II). hERG encoded the pore-forming $\alpha$ subunit of the delayed rectifier potassium channel and its inhibitors widely used for assessing proarrhythmic risk for novel drugs. Thus, the glucose compounds were safe from proarrhythmic risks. Their toxicity levels $\left(\mathrm{LD}_{50}\right)$ were also in an acceptable range. Thus, these glucose molecules were potentially labile in respect of ADMET risk properties (scores). 
Table 3. ADMET calculation of glucose compounds 1-4.

\begin{tabular}{|c|c|c|c|c|c|c|c|c|c|}
\hline \multirow{3}{*}{ Drug } & \multicolumn{2}{|c|}{ Absorption } & \multicolumn{3}{|c|}{ Distribution } & \multirow{3}{*}{$\begin{array}{c}\text { Metabolism } \\
\text { CYP3A4 } \\
\text { substrate }\end{array}$} & \multirow{3}{*}{$\begin{array}{c}\text { Excretion } \\
\text { Total } \\
\text { clearance }\end{array}$} & \multirow{3}{*}{$\begin{array}{c}\text { Toxicity } \\
\text { hERG } \\
\text { inhibitor }\end{array}$} & \multirow{3}{*}{$\begin{array}{l}\text { Toxicity } \\
\left(\mathrm{LD}_{50}\right)\end{array}$} \\
\hline & $\mathrm{C} 2 \mathrm{P}$ & HIA & P- & BBB & $\mathrm{CNS}$ & & & & \\
\hline & & & gpI & \multicolumn{2}{|c|}{ permeability } & & & & \\
\hline 1 & 0.067 & 59.55 & No & -0.833 & -3.547 & No & 1.161 & No & 2.089 \\
\hline 2 & 0.831 & 82.49 & No & -0.212 & -3.150 & No & 1.246 & No & 2.052 \\
\hline 3 & -0.195 & 51.80 & No & -1.262 & -4.342 & No & 0.769 & No & 1.916 \\
\hline 4 & 0.906 & 75.38 & No & -1.187 & -4.250 & No & 0.788 & No & 1.721 \\
\hline FCZ & 1.191 & 87.82 & No & -1.200 & -3.221 & No & 0.386 & No & 2.210 \\
\hline
\end{tabular}

Having suitability in ADMET properties compounds 1-4 were checked for their in silico druglikeness properties. Drug-likeness calculation was conducted by the SwissADME programme $[47,56]$, and presented in Table 4. All the molecules had molecular weight below 500; the number of rotatable bonds, hydrogen bond donor and acceptors were in good agreement with the Lipinski rule [55]. According to this Rule of 5, during drug discovery setting it was predicted that poor absorption or permeation i.e. dug-likeness was more observed when there were more than $5 \mathrm{H}$-bond donors, $10 \mathrm{H}$ bond acceptors, the molecular weight of the compound was greater than 500, and the $\log \mathrm{P}(\mathrm{C} \log \mathrm{P})$ calculated was greater than 5 [57]. More importantly, the topological polar surface area (TPSA) of all the compounds was found below $140 \AA^{2}$ (Figure 4). The chemical compounds which generally showed false positive results in high-throughput screening experiments were characterized by the Panassay interference (PAINS) compounds such as quinones, enones, phenol-sulphonamides etc. However, all the glucose compounds did not violate PAINS. Thus, ADME along with SwissADME indicated the better drug-likeness conditions for acetyl esters $(1 \& 3)$ and ethyl ethers $(2 \& 4)$ of glucopyranose and glucopyranoses under consideration.

Table 4. Drug-likeness behaviours of 1-4 predicted by SwissADME.

\begin{tabular}{lccccccccc}
\hline Drug & $\begin{array}{c}\text { HB } \\
\text { acceptors }\end{array}$ & $\begin{array}{c}\text { HB } \\
\text { donors }\end{array}$ & $\begin{array}{c}\text { NR } \\
\text { bonds }\end{array}$ & $\begin{array}{c}\text { TPSA } \\
\left(\mathbf{\AA}^{\mathbf{2}}\right)\end{array}$ & $\begin{array}{c}\mathbf{L o g} \\
\mathbf{P o} / \mathbf{w}\end{array}$ & $\begin{array}{c}\text { MW } \\
(\mathbf{g} / \mathbf{m o l})\end{array}$ & $\begin{array}{c}\text { Lipinski } \\
\text { rule }\end{array}$ & $\begin{array}{c}\text { PAINS } \\
\text { alerts }\end{array}$ & BS \\
\hline $\mathbf{1}$ & 7 & 2 & 4 & 94.45 & -0.07 & 262.26 & Yes & 0 & 0.55 \\
$\mathbf{2}$ & 6 & 2 & 4 & 77.38 & 0.32 & 248.27 & Yes & 0 & 0.55 \\
$\mathbf{3}$ & 7 & 3 & 4 & 105.45 & -1.17 & 236.22 & Yes & 0 & 0.55 \\
$\mathbf{4}$ & 6 & 3 & 4 & 88.38 & -0.88 & 222.24 & Yes & 0 & 0.55 \\
\hline \\
*HB = Hydrogen bond, NR $=$ number of rotatable; TPSA indicates polar surface area; BS $=$ bioavailability \\
score
\end{tabular}

e-ISSN: 2289-7771 

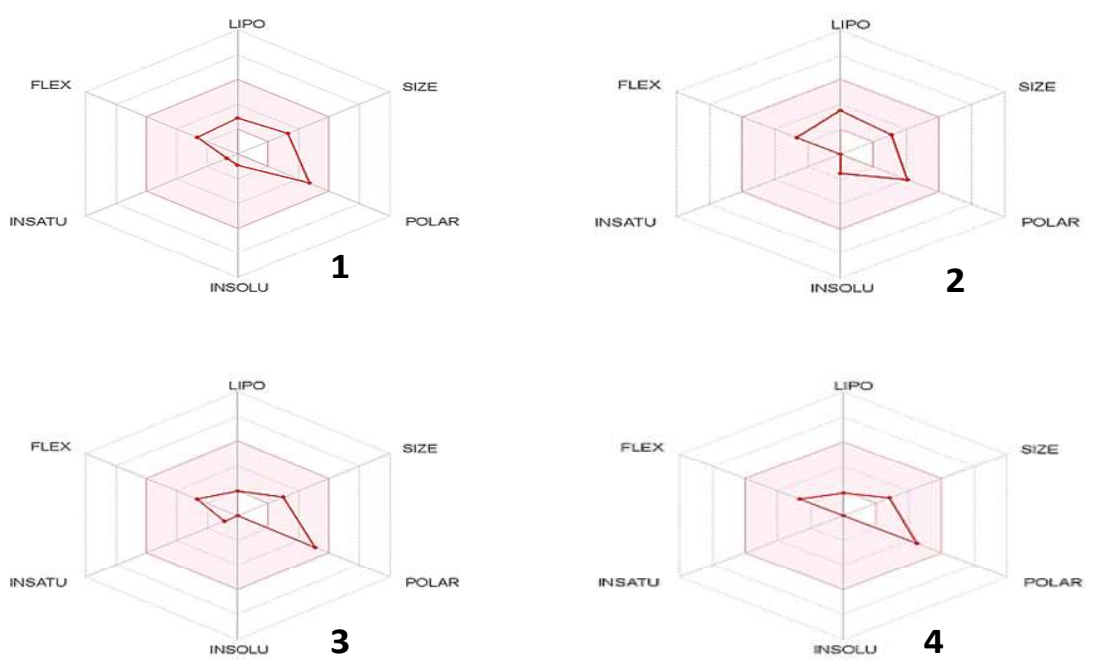

Figure 4. The polar surface area of 6-O-substituted glucose compounds 1-4.

\section{Conclusion}

For comparative DFT studies, 6- $O$-substituted glucofuranose and glucopyranose molecules were examined. Predicted activity spectrum for substances i.e. PASS suggested that glucose in the sixmembered pyranose form was more prone to biological properties as compared to its five-membered furanose form. In this respect, their structural, thermodynamic and chemical reactivities were calculated and discussed. Like fluconazole, these compounds were P-glycoprotein non-inhibitor. More importantly, all the substituted glucose were non-inhibitor of human Ether-a-go-go Related Gene (hERG; I \& II) and thus, these glucose compounds were safe from lethal proarrhythmic risks. Their toxicity levels $\left(\mathrm{LD}_{50}\right)$ are also in acceptable range. Drug-likeness calculations indicated that these compounds were in agreement with Lipinski's rule and did not violate PAINS. All these results may help to investigate further for their applications as versatile pharmaceutical agents.

\section{References}

[1] Tiwari, V. K. (2021). Development of diverse range of biologically relevant carbohydrate-containing molecules: Twenty years of our journey. The Chemical Record, https://doi.org/10.1002/tcr.202100058

[2] Campo, V. L., \& Carvalho, I. (2013). In: Click Chemistry in Glycoscience (New Developments and Strategies), 325-357. https://doi.org/10.1002/9781118526996.ch13

[3] Matin, M. M., Sharma, T., Sabharwal, S. G., \& Dhavale, D. D. (2005). Synthesis and evaluation of glycosidase inhibitory activity of 5-hydroxy substituted isofagomine analogues. Organic \& Biomolecular Chemistry, 3(9), 1702-1707. https://doi.org/10.1039/b418283a

[4] Dhavale, D. D., Matin, M. M., Sharma, T., \& Sabharwal, S. G. (2004). Synthesis and evaluation of glycosidase inhibitory activity of octahydro-2H-pyrido[1,2-a]pyrimidine and octahydro-imidazo[1,2a]pyridine bicyclic diazasugars. Bioorganic \& Medicinal Chemistry, 12(15), 4039-4044. https://doi.org/10.1016/j.bmc.2004.05.030

[5] Mehta, D. P., Ichikawa, M., Salimath, P. V., Etchison, J. R., Haak, R., Manzi, A., \& Freeze, H. H. (1996). A lysosomal cysteine proteinase from Dictyostelium discoideum contains N-acetylglucosamine-1phosphate bound to serine but not mannose-6-phosphate on N-linked oligosaccharides. Journal of Biological Chemistry, 271, 10897-10903. https://doi.org/10.1074/jbc.271.18.10897

[6] Kabir, A. K. M. S., Matin, M. M., Mridha, M. A. U., \& Shahed, S. M. (1998). Antifungal activities of some methyl 6-O-trityl- $\alpha$-D-mannopyranosides. The Chittagong University Journal of Science, 22(1), 41-46.

e-ISSN: 2289-7771

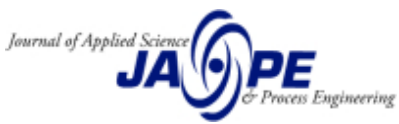


ISSN: $1561-1167$

[7] Stowell, S. R., Karmakar, S., Stowell, C. J., Dias-Baruffi, M., Mcever, R. P., \& Cummings, R. D. (2007). Human galectin-1,-2, and-4 induce surface exposure of phosphatidylserine in activated human neutrophils but not in activated T cells. Blood, 109, 219-227. https://doi.org/10.1182/blood-2006-03-007153

[8] Matin, M. M., Bhuiyan, M. M. H., Hossain, M. M., \& Roshid, M. H. O. (2015). Synthesis and comparative antibacterial studies of some benzylidene monosaccharide benzoates. Journal of the Turkish Chemical Society Section A: Chemistry, 2(4), 12-21. https://doi.org/10.18596/jotcsa.83708

[9] Dodd, R. B., \& Drickamer, K. (2001). Lectin-like proteins in model organisms: implications for evolution of carbohydrate-binding activity. Glycobiology, 11, 71R-79R. https://doi.org/10.1093/glycob/11.5.71R

[10] Slovin, S. F., Keding, S. J., \& Ragupathi, G. (2005). Carbohydrate vaccines as immunotherapy for cancer. Immunology \& Cell Biology, 83, 418-428. https://doi.org/10.1111/j.1440-1711.2005.01350.x

[11] Kim, H. J., Kang, S. H., Choi, S. S., \& Kim, E. S. (2017). Redesign of antifungal polyene glycosylation: engineered biosynthesis of disaccharide-modified NPP. Applied Microbiology \& Biotechnology, 101, 5131-5137. https://doi.org/10.1007/s00253-017-8303-8

[12] Aragao-Leoneti, V., Campo, V. L., Gomes, A. S., Field, R. A., Carvalho, I. (2010). Application of copper (I)-catalysed azide/alkyne cycloaddition (CuAAC) 'click chemistry'in carbohydrate drug and neoglycopolymer synthesis. Tetrahedron, 66, 9475-9492. https://doi.org/10.1016/j.tet.2010.10.001

[13] Kabir, A. K. M. S., Matin, M. M., \& Kawsar, S. M. A. (1998). Synthesis and antibacterial activities of some uridine derivatives. The Chittagong University Journal of Science, 22(1), 13-18. ISSN: 1561-1167

[14] Stowell, S. R., Qian, Y., Karmakar, S., Koyama, N. S., Dias-Baruffi, M., Leffler, H., McEver, R. P., \& Cummings, R. D. (2008). Differential roles of galectin-1 and galectin-3 in regulating leukocyte viability and cytokine secretion. Journal of Immunology, 180, 3091-3102. https://doi.org/10.4049/jimmunol.180.5.3091

[15] Matin, M. M., \& Ibrahim, M. (2010). Synthesis of some methyl 4-O-octanoyl- $\alpha$-L-rhamnopyranoside derivatives. Journal of Applied Sciences Research, 6(10), 1527-1532. ISSN: 1819-544X

[16] Matin, M. M. (2008). One step intramolecular cyclization of diol via mesylation: Efficient synthesis of sugar derived [1,4]oxazepanes. Journal of the Bangladesh Chemical Society, 21(2), 179-183. ISSN: 1022$016 \mathrm{X}$

[17] Lutz, J. F. (2007). 1,3-Dipolar cycloadditions of azides and alkynes: a universal ligation tool in polymer and materials science. Angewandte Chemie International Edition, 46, 1018-1025. https://doi.org/10.1002/anie.200604050

[18] Pöhnlein, M., Slomka, C., Kukharenko, O., et al. (2014). Enzymatic synthesis of amino sugar fatty acid esters. European Journal of Lipid Science \& Technology, 116, 423-428. https://doi.org/10.1002/ejlt.201300380

[19] Grzywacz, D., Liberek, B., \& Myszka, H. (2020). Synthesis, modification and biological activity of diosgenyl $\quad \beta$-d-glycosaminosides: An overview. $\quad$ Molecules, $25, \quad$ e5433. https://doi.org/10.3390/molecules25225433

[20] Wolfrom, M. L., \& Bhat, H. M. (1967). Trichloroacetyl and trifluoroacetyl as N-blocking groups in nucleoside synthesis with 2-amino sugars. Journal of Organic Chemistry, 32, 1821-1823. https://doi.org/10.1021/jo01281a025

[21] Matin, M. M. (2006). N-Butylation and N-acetylation of a sugar-derived $\beta$-aminoester. The Chittagong University Journal of Science, 30(1), 35-39. ISSN: 1561-1167

[22] Imran, M., Shah, M. R., Ullah, F., Ullah, S., Sadiq, A., Ali, I., Ahmed, F., \& Nawaz, W. (2017). Doubletailed acyl glycoside niosomal nanocarrier for enhanced oral bioavailability of Cefixime. Artificial Cells, Nanomedicine, and Biotechnology, 45(7), 1440-1451. https://doi.org/10.1080/21691401.2016.1246451

[23] Matin, M. M., \& Iqbal, M. Z. (2008). Synthesis and antimicrobial evaluation of some methyl 4-Odecanoyl- $\alpha$-L-rhamnopyranoside derivatives. Proceedings of the Bangladesh Chemical Congress, 254263. https://doi.org/10.13140/2.1.3710.8008

[24] Muzzalupo, R., Tavano, L., \& La Mesa, C. (2013). Alkyl glucopyranoside-based niosomes containing methotrexate for pharmaceutical applications: evaluation of physico-chemical and biological properties. International Journal of Pharmaceutics, Vol.458, 224-229. http://doi.org/10.1016/j.ijpharm.2013.09.011

[25] Bhuiyan, M. M. H., Matin, M. M., Rahman, A. F. M. H., \& Alam, M. R. (2019). Synthesis and biological evaluation of sugar induced thiazole derivatives. The Chittagong University Journal of Science, Vol.41, No.1, 68-84. http://doi.org/10.3329/cujs.v41i1.51915

[26] Matin, M. M., \& Ibrahim, M. (2006). Synthesis of 2,3-di-O-substituted derivatives of methyl 4-O-acetyl- $\alpha$ L-rhamnopyranoside. The Chittagong University Journal of Science, 30(2), 67-76. ISSN: 1561-1167

e-ISSN: 2289-7771

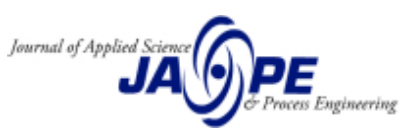


[27] Singh, D., Pradhan, M., Nag M., \& Singh, M. R. (2015). Vesicular system: versatile carrier for transdermal delivery of bioactives. Artificial Cells, Nanomedicine, and Biotechnology, 43, 282-290. https://doi.org/10.3109/21691401.2014.883401

[28] Kabir, A. K. M. S., \& Matin, M. M. (1994). Regioselective acylation of a derivative of L-rhamonse using the dibutyltin oxide method. Journal of the Bangladesh Chemical Society, 7(1), 73-79. ISSN: 1022-016X

[29] Matin, M. M., Bhuiyan, M. M. H., Azad, A. K. M. S., Bhattacharjee, S. C. \& Rashid, M. H. O. (2014). Synthesis and antimicrobial studies of 6-O-lauroyl-1,2-O-isopropylidene- $\alpha$-D-gluco-furanose derivatives. Chemistry \& Biology Interface, 4(4), 223-231. ISSN: 2249-4820

[30] Matin, M. M., Bhattacharjee, S. C., Hoque, M. S., \& Ahamed, F. (2019). Antibacterial activity of some medicinal plants against carbapenem-resistant Acinetobacter baumannii isolated from patients. European Journal of Pharmaceutical and Medical Research, 6(7), 111-116. ISSN: 2394-3211

[31] Matin, M. M., Roshid, M. H. O., Bhattacharjee, S. C., \& Azad, A. K. M. S. (2020). PASS predication, antiviral, in vitro antimicrobial, and ADMET studies of rhamnopyranoside esters. Medical Research Archives, Vol.8, No.7, 2165. https://doi.org/10.18103/mra.v8i7.2165

[32] Bhattacharjee, S. C., Matin, M. M., \& Nasiruddin, M. (2019). Insecticidal effects of two medicinal plants Polygonum hydropiper L. and Abrus precatorius L. leaves against the rice weevil Sitophilus oryzae L. (Coleoptera: Curculionidae). Journal of Biodiversity Conservation and Bioresource Management, 5(2), 107-114. https://doi.org/10.3329/jbcbm.v5i2.44921

[33] Filimonov D. A., Lagunin A. A., Gloriozova T. A., Rudik A. V., Druzhilovskii D. S., Pogodin P. V., \& Poroikov V. V. (2014). Prediction of the biological activity spectra of organic compounds using the PASS online web resource. Chemistry of Heterocyclic Compounds, 50(3), 444-457. https://doi.org/10.1007/s10593-014-1496-1

[34] Chowdhury, S. A., Chakraborty, P., Kawsar, S. M. A., Bhuiyan, M. M. H., \& Matin, M. M. (2018). Regioselective acylation, PASS prediction and antimicrobial properties of some protected glucopyranosides, Journal of the Bangladesh Chemical Society, 30(1), 1-9. ISSN: 1022-016X

[35] Matin, M. M., Nath, A. R., Saad, O., Bhuiyan, M. M. H., Kadir, F. A., Abd Hamid, S. B., Alhadi, A. A., Ali, M. E., \& Yehye, W. A. (2016). Synthesis, PASS-predication and in vitro antimicrobial activity of benzyl 4-O-benzoyl- $\alpha$-L-rhamnopyranoside derivatives, International Journal of Molecular Sciences, 17(9), 1412. https://doi.org/10.3390/ijms17091412

[36] Rahim, A., Bhuiyan, M. M. H., Matin, M. M., Ali, R., \& Kabir, E. (2018). Synthesis of 2-phenylchromen4-one derivatives by conventional and microwave assisted techniques and their antimicrobial evaluation, International Journal of Chemical Studies, 6(1), 1644-1647. ISSN: 2349-8528

[37] Matin, M. M., Islam, N., Siddika, A., \& Bhattacharjee, S. C. (2021). Regioselective synthesis of some rhamnopyranoside esters for PASS predication, and ADMET studies. Journal of the Turkish Chemical Society Section A: Chemistry, 8(1), 363-374. https://doi.org/10.18596/jotcsa.829658

[38] Islam, N., Islam, M. D., Rahman, M. R., \& Matin, M. M. (2021). Octyl 6-O-hexanoyl- $\beta$-Dglucopyranosides: Synthesis, PASS, antibacterial, in silico ADMET, and DFT studies. Current Chemistry Letters, 10(4), 413-426. https://doi.org/10.5267/j.ccl.2021.5.003

[39] Hanee, U., Rahman, M. R., \& Matin, M. M. (2021). Synthesis, PASS, in silico ADMET, and thermodynamic studies of some galactopyranoside esters, Physical Chemistry Research, 9(4), 591-603. https://doi.org/10.22036/pcr.2021.282956.1911

[40] Frisch, M. J., Trucks, G. W., Schlegel, H. B., Scuseria, G. E., Robb, M. A., et al. (2013). Gaussian 09W, Revision D.01. Gaussian, Inc., Wallingford CT.

[41] Uzzaman, M., Hasan, M. K., Mahmud, S., Fatema, K., \& Matin, M. M. (2021). Structure-based design of new diclofenac: Physicochemical, spectral, molecular docking, dynamics simulation and ADMET studies. Informatics in Medicine Unlocked, 25, 100677. https://doi.org/10.1016/j.imu.2021.100677

[42] Islam, F., Rahman, M. R., \& Matin, M. M. (2021). The effects of protecting and acyl groups on the conformation of benzyl $\alpha$-L-rhamnopyranosides: An in silico study. Turkish Computational and Theoretical Chemistry, 5(1), 39-50. https://doi.org/10.33435/tcandtc.914768

[43] Matin, M. M., \& Chakraborty, P. (2020). Synthesis, spectral and DFT characterization, PASS predication, antimicrobial, and ADMET studies of some novel mannopyranoside esters. Journal of Applied Science \& Process Engineering, 7(2), 572-586. https://doi.org/10.33736/jaspe.2603.2020

[44] Matin, M. M., \& Iqbal, M. Z. (2021). Methyl 4-O-(2-chlorobenzoyl)- $\alpha$-L-rhamnopyranosides: Synthesis, characterization, and thermodynamic studies. Orbital: The Electronic Journal of Chemistry, 13(1), 19-27. http://dx.doi.org/10.17807/orbital.v13i1.1532

[45] Azam, F., Alabdullah, N. H., Ehmedat, H. M., Abulifa, A. R., Taban, I., \& Upadhyayula, S. (2018).

e-ISSN: 2289-7771

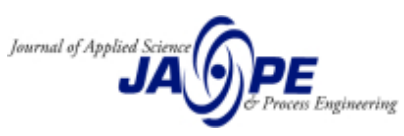


NSAIDs as potential treatment option for preventing amyloid $\beta$ toxicity in Alzheimer's disease: an investigation by docking, molecular dynamics, and DFT studies, Journal of Biomolecular Structure and Dynamics, 36, 2099-2117. https://doi.org/10.1080/07391102.2017.1338164

[46] Pires, D. E. V., Blundell, T. L., \& Ascher, D. B. (2015). pkCSM: predicting small-molecule pharmacokinetic properties using graph-based signatures. Journal of Medicinal Chemistry, 58(9), 40664072. https://doi.org/10.1021/acs.jmedchem.5b00104

[47] Daina, A., Michielin, O., \& Zoete, V. (2017). SwissADME: a free web tool to evaluate pharmacokinetics, drug-likeness and medicinal chemistry friendliness of small molecules. Scientific Report, 7, 42717. https://doi.org/10.1038/srep42717

[48] Cheng, F., Li, W., Zhou, Y., Shen, J., Wu, Z., Liu, G., et al. (2012). AdmetSAR: A comprehensive source and free tool for assessment of chemical ADMET properties. Journal of Chemical Information and Modeling, 52, 3099-3105. https://doi.org/10.1021/ci300367a

[49] Rahim, A., Bhuiyan, M. M. H., \& Matin, M. M. (2020). Microwave assisted efficient synthesis of some flavones for antimicrobial and ADMET studies. Journal of Scientific Research, 12(4), 673-685. http://dx.doi.org/10.3329/jsr.v12i4.45523

[50] Matin, M. M., Bhattacharjee, S. C., Chakraborty, P., \& Alam M. S. (2019). Synthesis, PASS predication, in vitro antimicrobial evaluation and pharmacokinetic study of novel n-octyl glucopyranoside esters, Carbohydrate Research, 485, 107812. https://doi.org/10.1016/j.carres.2019.107812

[51] Matin, M. M., Bhuiyan, M. M. H., Kabir, E., Sanaullah, A. F. M., Rahman, M. A., Hossain, M. E., \& Uzzaman, M. (2019). Synthesis, characterization, ADMET, PASS predication, and antimicrobial study of 6-O-lauroyl mannopyranosides. Journal of Molecular Structure, 1195, 189-197. https://doi.org/10.1016/j.molstruc.2019.05.102

[52] Awual, M. R. (2017). Novel nanocomposite materials for efficient and selective mercury ions capturing from wastewater. Chemical Engineering Journal, 307, 456-465. https://doi.org/10.1016/j.cej.2016.08.108

[53] Awual, M. R. (2017). New type mesoporous conjugate material for selective optical copper(II) ions monitoring \& removal from polluted waters. Chemical Engineering Journal, 307, 85-94. https://doi.org/10.1016/j.cej.2016.07.110

[54] Matin, M. M., Chakraborty, P., Alam M. S., Islam, M. M., \& Hanee, U. (2020). Novel mannopyranoside esters as sterol 14 $\alpha$-demethylase inhibitors: Synthesis, PASS predication, molecular docking, and $\begin{array}{lllll}\text { pharmacokinetic } \quad \text { studies. } & \text { Carbohydrate } & \text { Research, }\end{array}$ https://doi.org/10.1016/j.carres.2020.108130

[55] Matin, M. M., Hasan, M. S., Uzzaman, M., Bhuiyan, M. M. H., Kibria, S. M., Hossain, M. E., \& Roshid, M. H. O. (2020). Synthesis, spectroscopic characterization, molecular docking, and ADMET studies of mannopyranoside esters as antimicrobial agents. Journal of Molecular Structure, 1222, 128821. https://doi.org/10.1016/j.molstruc.2020.128821

[56] Matin, M. M., Uzzaman, M., Chowdhury, S. A., \& Bhuiyan, M. M. H. (2020). In vitro antimicrobial, physicochemical, pharmacokinetics, and molecular docking studies of benzoyl uridine esters against SARS-CoV-2 main protease. Journal of Biomolecular Structure and Dynamics, 1-13. https://doi.org/10.1080/07391102.2020.1850358

[57] Lipinski, C. A. (2004). Lead- and drug-like compounds: the rule-of-five revolution. Drug Discovery Today: Technologies, 1(4), 337-341. https://doi.org/10.1016/j.ddtec.2004.11.007 